\title{
Skin Permeability of Porcine Placenta Extracts and Its Physiological Activities
}

\author{
JeungHi Han, Mi-Ryung Kim¹, Yooheon Park, Yang Hee Hong, and Hyung Joo Suh* \\ Department of Food and Nutrition, Korea University, Seoul 136-703, Korea \\ ${ }^{1}$ Department of Home Economics, Korea University, Seoul 136-703, Korea
}

\begin{abstract}
We investigated the skin permeability and various biological activities of porcine homogenate of placenta (HP) with the highest protein contents $(452.89 \mu \mathrm{g} / \mathrm{mg})$. The content of protein in subcritical extract of HP (SPE) was decreased from the initial content of $452.9 \mu \mathrm{g} / \mathrm{mg}$ to $262.7 \mu \mathrm{g} / \mathrm{mg}$ at $3 \mathrm{~h}$ subcritical extract. The contents of amino type nitrogen (A-N) were sharply increased from $35.1 \mu \mathrm{g} / \mathrm{mg}$ of initial content to $305.9 \mu \mathrm{g} / \mathrm{mg}$ at $3 \mathrm{~h}$ subcritical extract. The HP showed a noticeable activity in terms of antioxidant capacity for ferric reducing antioxidant power (FRAP) assay and especially for 2,2'-Azinobis(3-ethylbenzothiazoline-6-sulfonic acid) (ABTS) method. HP, SPE-0.5, SPE-2 and SPE-3 showed inhibitory effect on elastase activities with an $\mathrm{IC}_{50}$ of $46.1,42.9,31.6$ and $34.7 \mu \mathrm{g} / \mathrm{mL}$, respectively. SPEs showed more significantly inhibitory effect than HP $(p<0.05)$. The skin permeability of the SPEs was higher than that of the HP. SPE-3 showed highest skin permeation and the permeability was significantly higher than that of HP. SPE-2 also showed significantly higher permeation than HP after $4 \mathrm{~h}$. As expected, increase of extraction time significantly increased skin permeability in the subcritical extract of HP (SPE). From these results, in terms of cost and source availability, porcine placenta extracted with subcritical extraction has advantages over untreated PE and have potential as a cosmetic ingredient.
\end{abstract}

Key words: placenta extract, radical scavenging activity, tyrosinase, elastase

\section{Introduction}

The placenta is a temporary organ that is present in females during gestation and supplies oxygen and nutrients to the developing fetus. The placenta is discharged from the mother's body when the fetus is born. The nutritional substances including bioactive compounds therein, known as the placenta extract (PE), can be extracted. The placenta is considered as a reservoir of cytokines, hormones, bioactive peptides, enzymes, growth factors, vitamins and minerals (Togashi et al., 2002). PE also contains many valuable bioactive compounds that have various biocapabilities, including inhibition of aging, inflammation, sunburn, gene mutation, anaphylacticity and oxidation (Kim et al., 2003). PE has been used as a biomedicine for wound healing in Korean folk medicine (Hong et al., 2010; Nath and Bhattacharyya, 2007), and the immunomodulatory effects of human PE have been demonstrated in multiple studies (Fang et al., 2007; Lee et al., 2013).

*Corresponding author: Hyung Joo Suh, Department of Food and Nutrition, Korea University, Seoul 136-703, Korea. Tel: 82-2940-2853, Fax: 82-2-940-2859, E-mail: suh1960@korea.ac.kr
Placenta extracts (PEs) have been used to cosmetic and pharmaceutical products for whitening effect and oxidative stress related diseases (Togashi et al., 2002). When it comes to the sources of placenta tissues, human placenta extracts have been the most highly favored source of placenta extract. However, the use of human placenta extract is limited for the ethical issue in collecting the human placenta. Alternatively, sheep placenta extracts have been used to replace human placenta extracts. But, the use of sheep placenta extracts carries the risk of spongiform encephalopathy (Wrathall, 1997). To avoid these problems, porcine placenta are emerging as a new industrial source of placenta extracts. Porcine placenta extract is regarded as a suitable alternative of human placenta extract due to high genetical homogeneity between human and porcine placenta (McGregor et al., 2005; Pruitt et al., 1994).

Recently, benefits of the topical use of PE on chronic and non-healing wounds have been reported (Tiwary et al., 2006). PE also features as a component of various skin ointments and was used for skin vitalizing, nourishment, melanocyte growth and pigment inducing activities (Pal et al., 2002) as well as for the treatment of skin 
hypersensitivity like dermatitis and psoriasis. Although porcine PE-containing cosmetic materials have been claimed to provide enhanced skin permeability and to exert biological activities, few studies have been carried out on the skin permeability and biological activities.

For the use of porcine PE as a cosmeceutical, dermal absorption is an important factor for cosmetic ingredients. In this study, we investigated the skin permeability and various biological activities of porcine PE as cosmeceutical ingredients.

\section{Materials and Methods}

\section{Preparation of porcine placenta extract (PPE)}

The pig placentas obtained from normal delivery were washed thoroughly with sodium hydrate solution $(\mathrm{NaOH})$ and chopped into small pieces $(<1 \mathrm{~cm})$, and the sliced tissues were resuspended in PBS and freeze-dried to eliminate any residual liquid (Georgieva et al., 1995). Sliced porcine placenta was homogenized by blender (HR-2084, Philips Electronics N.V., Netherland) for $10 \mathrm{~min}$ and centrifuged. Precipitate (water: 95\%, protein: $5 \%$ ) mixed with water $(700 \mathrm{~mL})$ and subcritical extracted by subcritical extractor system (DIONEX ASE 100, Dionex corporation, USA). During extraction, the pressure was maintained 375 bar. Extractions were performed for $30 \mathrm{~min}$, $2 \mathrm{~h}$ and $3 \mathrm{~h}$. The extract was centrifuged at $2,800 \mathrm{~g}$ for $20 \mathrm{~min}$. The supernatants were concentrated using a vacuum evaporator at $40^{\circ} \mathrm{C}$ and lyophilized to produce the PPE.

\section{Stimulated gastrointestinal digestion procedures}

A gastrointestinal digestion study was performed by using the method developed by Gil-Izquierdo et al. (GilIzquierdo et al., 2002). The first part was simulating gastric digestion in vitro, based on the principle of equilibrium dialysis. Briefly, tri-distilled water $(80 \mathrm{~mL})$ was added to dried sample and the $\mathrm{pH}$ was adjusted 2.0 by $\mathrm{HCl}$. The total volume was adjusted to $85 \mathrm{~mL}$ by tridistilled water if less than $85 \mathrm{~mL}$. Then, $3.0 \mathrm{~mL}$ freshly prepared pepsin (Sigma Chemical Co., USA) solution was added. The mixture was then incubated in shaking water bath at $37^{\circ} \mathrm{C}$ for $2 \mathrm{~h}$.

After simulating gastric digestion, pancreatic digestion as the second part of the experiment was brought out. The combined pepsin digested pancratine-bile extract mixture (Sigma Chemical Co., USA) was changed to be $\mathrm{pH} 7.0$ by using $\mathrm{NaOH}$ solution. Five $\mathrm{mL}$ of pancreatic-bile ext- ract mixture was added and then the incubation was continued for additional $2 \mathrm{~h}$.

\section{Skin permeability test across Franz-type diffusion cell models}

Skin permeation was determined by the method of Sonavane et al. (2008), with certain modifications. Male Sprague-Dawley (SD) rats, weighing 250 to $300 \mathrm{~g}$ (Nara Bio Animal Center, Korea), were used for the study. The hair was removed from rats with an electric clipper and an electric razor 1 day before the study. Rats were anaesthetized with ether anesthesia and decapitated. The skin was exercised immediately. The skin was cut into in to small pieces $(3 \times 3 \mathrm{~cm})$. A small piece of skin put between donor cell and receptor cell of Franz-type diffusion cell. Then, $4.9 \mathrm{~mL}$ of $0.1 \mathrm{M}$ sodium phosphate buffer ( $\mathrm{pH} 7.4$ ) was used as a receptor medium, and $100 \mu \mathrm{L}$ of HP and SPE were placed on the donor side. The receptor medium was kept at $37^{\circ} \mathrm{C}$ and stirred with a magnetic stirrer at $400 \mathrm{rpm}$. The protein content of the transports was determined by using the bicinchoninic acid (BCA) method, according to the manufacturer's instructions (Pierce Chemicals Ltd, USA). Bovine serum albumin was used as a standard.

\section{Bioavailability of porcine planceta by intestinal sac}

Everted intestinal sac experiments were performed according to the method described by Tandon and Prakash (1972) with some modifications. Male Sparague-Dawley rats weighting 220-250 g (about $7 \mathrm{wk}$ ) fasted overnight with free access of water. The jejunum was collected after urethane anesthesia. Collected jejunum was flushed with ice-cold Krebs-Henseleit into a bicarbonate (KHB) buffer to remove intestinal contents. The jejunum was gently stretched and cut into segments $(10 \mathrm{~cm}$ long each). Each of the sacs was carefully everted with a glass rod. The serosal fluid transfer was reflected to the increase in the volume of fluid in the gut. Total amount of transported extract sample was expressed as total protein contents. Each sac ligated at one end. $1 \mathrm{~mL} \mathrm{KHB}$ buffer was added to the sacs, after which the other end was ligated to seal the sac. The sacs were contained to conical tubes with continuous supply of $5 \% \mathrm{CO}_{2}$ and $95 \% \mathrm{O}_{2}$ and the other for removal and addition of the serosal fluid. The conical tubes were incubated in a water bath at $37^{\circ} \mathrm{C}$ for an hour. Intestinal transport of the sample was expressed as $\mathrm{mg}$ of protein $/ \mathrm{g}$ tissue dry weight. The protein contents of the transports were determined according to the BCA method. 


\section{Protein and amino nitrogen contents}

Protein content was assayed using the bicinchoninic acid (BCA) method, according to the manufacturer's instructions (Pierce Chemicals Ltd, USA) using bovine serum albumin as the standard. The contents of amino type nitrogen (A-N) were determined by the methods of TNBS. Modified methods of Adler-Nissen (1979) were used to determine $\alpha$-amino acid content. Properly diluted samples $(125 \mu \mathrm{L})$ were mixed thoroughly with $2.0 \mathrm{~mL}$ of 0.2125 $\mathrm{M}$ phosphate buffer, $\mathrm{pH} 8.2$, followed by the addition of $1.0 \mathrm{~mL}$ of $0.01 \%$ TNBS solution. The mixtures were then placed in a water bath at $50^{\circ} \mathrm{C}$ for $30 \mathrm{~min}$ in the dark. The reaction was terminated by adding $2.0 \mathrm{~mL}$ of $0.1 \mathrm{M}$ sodium sulfite. The mixtures were cooled down at ambient temperature for $15 \mathrm{~min}$. The absorbance was measured at 420 $\mathrm{nm}$ and R-amino acid was expressed in terms of L-leucine.

\section{Antioxidant activities of porcine placenta extract}

The ABTS radical scavenging activity was determined as described by Wang and Xiong (2005), with slight modification. The antioxidant activities of the test samples were expressed as $\mathrm{IC}_{50}$, i.e., the amount of tested extract required for a $50 \%$ decrease in the absorbance of the ABTS radicals. The ferric reducing antioxidant power (FRAP) method was performed as described by Benzie and Strain (1996). $\Delta A$ is proportional to the combined (total) ferric reducing/antioxidant power (FRAP value) of the antioxidants in the sample.

\section{Inhibition activity of porcine placenta extract on tyrosinase}

The assay based on Mason's method (1955) was adapted to a 96-well plate: $70 \mathrm{~mL}$ of $0.1 \mathrm{M}$ phosphate buffer $\mathrm{pH} 6.8$ (PBS), $30 \mathrm{~mL}$ of mushroom tyrosinase diluted in phosphate buffer (167 units $/ \mathrm{mL}$ ) and various concentration of different test samples those were dissolved in $20 \mathrm{~mL}$ dimethyl sulfoxide (DMSO), were placed in 96-well plates for $5 \mathrm{~min}$ pre-incubation at $37^{\circ} \mathrm{C}$. L-DOPA (100 $\mu \mathrm{g} / \mathrm{mL}$ ) was added to start the enzymatic reaction. Optical density (OD) at $492 \mathrm{~nm}$ was measured by using microplate reader (INFINITE M200 Nanoquant) to observe dopachrome formation for $10 \mathrm{~min}$. The percentage of inhibition is calculated by the following equation,

$$
\% \text { inhibition }=[(A-B)-(C-D)] /(A-B) \times 100
$$

A: OD at $492 \mathrm{~nm}$ with tyrosinase but without test substance; B: OD at $492 \mathrm{~nm}$ without test substance and tyrosinase; C: OD at $492 \mathrm{~nm}$ with test substance and tyrosinase; D: OD at $492 \mathrm{~nm}$ with/ test substance without tyrosinase
(Zhang et al., 2007).

\section{Inhibition activity of porcine placenta extract on elastase}

The assay was carried out based on the method of James (Kraunsoe et al., 1996). One $\mu \mathrm{g}$ porcine pancreatic elastase type IV (PPE) diluted in $0.2 \mathrm{M}$ Tris-HCL buffer ( $\mathrm{pH} \mathrm{8.0).}$ $0.2 \mathrm{M}$ Tris-HCL buffer (pH 8.0), $1 \mu \mathrm{g} / \mathrm{mL}$ PPE, $0.8 \mathrm{mM}$ $\mathrm{N}$-succinyl-(Ala) $)_{3}-p$-nitoroanilide sample mixed and incubated $20 \mathrm{~min}$ at $25^{\circ} \mathrm{C}$. Optical density (OD) at $410 \mathrm{~nm}$ was measured on micro-plate reader (INFINITE M200 Nanoquant).

$$
\% \text { inhibition }=[(A-B)-(C-D)] /(A-B) \times 100
$$

A: OD at $410 \mathrm{~nm}$ with elastase but without test substance; B: OD at $410 \mathrm{~nm}$ without test substance and elastase; C: OD at $410 \mathrm{~nm}$ with test substance and elastase; D: OD at $410 \mathrm{~nm}$ with/ test substance but without elastase.

\section{Statistical analysis}

The results were expressed as the mean \pm standard deviation (SD). The statistical analysis was performed with the Statistical Package for Social Sciences (SPSS, SPSS Inc., Chicago, IL, USA). The significance of the differences was analyzed by using one-way analysis of variance (ANOVA) with Duncan's multiple range tests. Value of $p<0.05$ were considered as statistically significant.

\section{Results}

\section{Protein and amino-nitrogen (A-N) of porcine PE}

Fig. 1 shows the contents of protein and A-N in porcine PE. Homogenate of placenta (HP) showed the highest protein contents $(452.89 \mu \mathrm{g} / \mathrm{mg})$. Unexpectedly, as the extraction time increased, the contents of protein from subcritical extraction of HP (SPE) was significantly decreased The content of protein in SPE decreased from the initial content of $452.9 \mu \mathrm{g} / \mathrm{mg}$ to $262.7 \mu \mathrm{g} / \mathrm{mg}$ at $3 \mathrm{~h}$ subcritical extract. A-N content was sharply increased from $35.1 \mu \mathrm{g} /$ $\mathrm{mg}$ of initial content to $305.9 \mu \mathrm{g} / \mathrm{mg}$ at $3 \mathrm{~h}$ subcritical extract. These results suggest that an increase of extraction time is more beneficial for hydrolysis of protein in porcine $\mathrm{PE}$, while prolonged heating time results in decrease of protein contents.

\section{Antioxidant activities of porcine $\mathrm{PE}$}

The antioxidant activity of the porcine PE obtained after subcritical extraction was evaluated on the basis of ABTS 

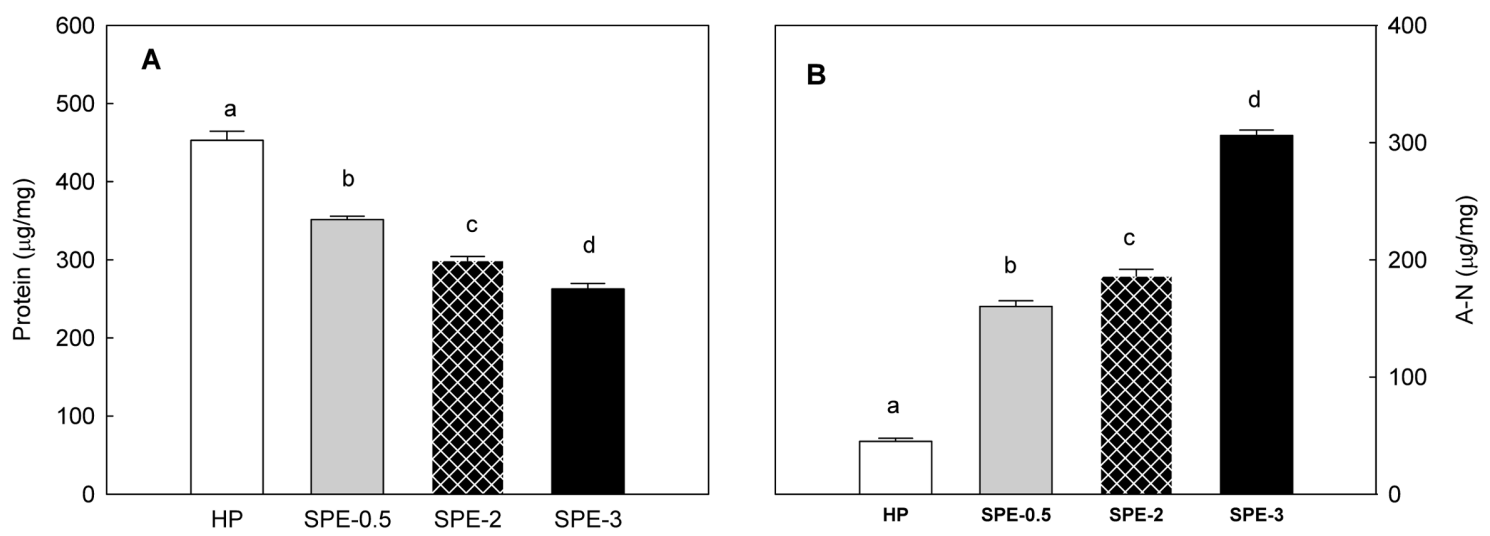

Fig. 1. Protein and A-N contents of porcine PE. Values were analyzed with a repeated measurement ANOVA. Each bar represented mean \pm SD. $n=3$. HP; Homogenate of placenta. SPE-0.5; subcritical extract of HP (SPE) for 0.5 h extraction, SPE-2; subcritical extract of HP (SPE) for 2 h extraction, SPE-3; subcritical extract of HP (SPE) for 4 h extraction
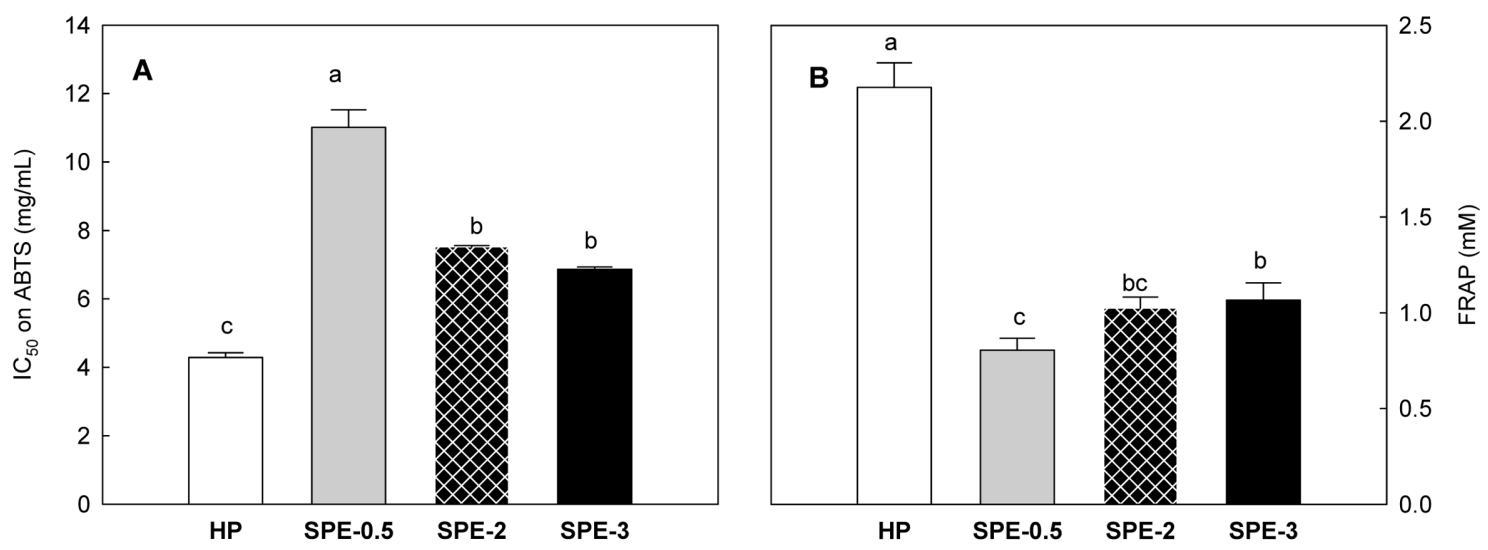

Fig. 2. Antioxidant activities of porcine PE. Values were analyzed with a repeated measurement ANOVA. Each bar represented mean \pm SD. $n=3$. HP; Homogenate of placenta. SPE-0.5; subcritical extract of HP (SPE) for 0.5 h extraction, SPE-2; subcritical extract of HP (SPE) for 2 h extraction, SPE-3; subcritical extract of HP (SPE) for 4 h extraction

radical scavenging ability (Fig. 2A) and Fe reducing capacity (FRAP) (Fig. 2B). The HP showed a noticeable activity in terms of antioxidant capacity for both measurement methods, FRAP and especially ABTS. HP exhibited relatively higher ABTS $\left(\mathrm{IC}_{50}, 4.3 \mathrm{mg} / \mathrm{mL}\right)$ radical scavenging activities than SPE $(6.7-11.0 \mathrm{mg} / \mathrm{mL})$. And FRAP capacity of HP (2.2 $\mathrm{mM})$ was also significantly higher than SPE (0.8-1.5 mM).

Increase of subcritical extraction time gave rise to a noticeable increase in the antioxidant capacity for both measurement methods, ABTS and especially FRAP. In the case of SPE, the ability of the extract to scavenge ABTS radicals significantly decreased in the order SPE- $3=$ SPE- 2 $>$ SPE- $0.5(p<0.05)$. The FRAP capacity of SPE decreased in the order SPE-3 $>$ SPE- $2 \geq$ SPE-0.5 $(p<0.05)$.

Inhibitory activities against tyrosinase and elastase Tyrosinase and elastase inhibitors might be clinically useful for the treatment of some dermatological diseases associated with melanin hyperpigmentation and important in cosmetics for depigmentation, anti-wrinkle and loss of elasticity.

All extracts (HP and SPEs) were tested for their inhibition activities towards mushroom tyrosinase and porcine pancreatic elastase (Fig. 3). There was no inhibitory effect on tyrosinase (data not shown). As shown in Fig. 3, HP, SPE-0.5, SPE-2 and SPE-3 showed inhibitory effect on elastase activities with an $\mathrm{IC}_{50}$ of 46.1, 42.9, 31.6 and 34.7 $\mu \mathrm{g} / \mathrm{mL}$, respectively. SPEs showed more significantly inhibitory effect than HP $(p<0.05)$.

\section{Skin permeation across Franz-type type diffusion cell}

In vitro permeation experiments are a valuable adjunct to in vivo percutaneous absorption studies, and provide a convenient means for evaluating the permeation charac- 


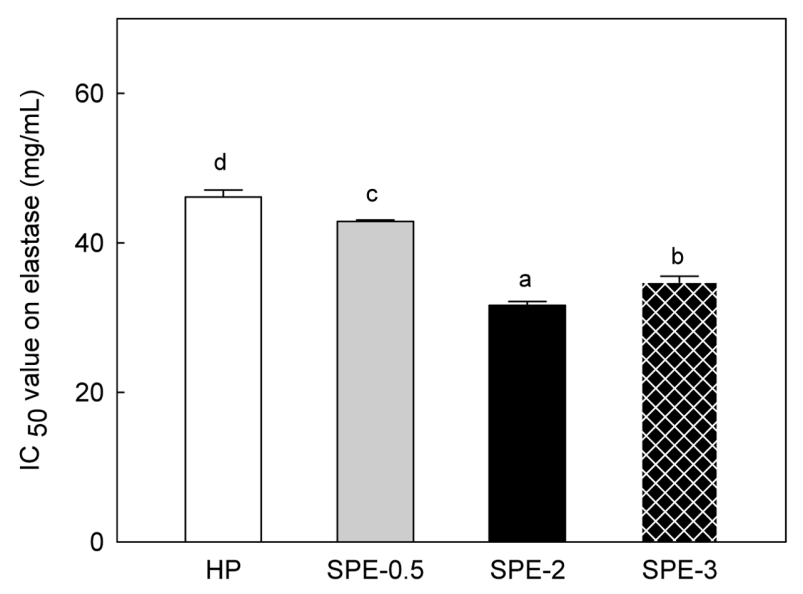

Fig. 3. Elastase inhibition activity of PE. Values were analyzed with a repeated measurement ANOVA. Each bar represented mean \pm SD. $n=3$. HP; Homogenate of placenta. SPE-0.5; subcritical extract of HP (SPE) for $0.5 \mathrm{~h}$ extraction, SPE-2; subcritical extract of HP (SPE) for 2 h extraction, SPE-3; subcritical extract of HP (SPE) for $4 \mathrm{~h}$ extraction

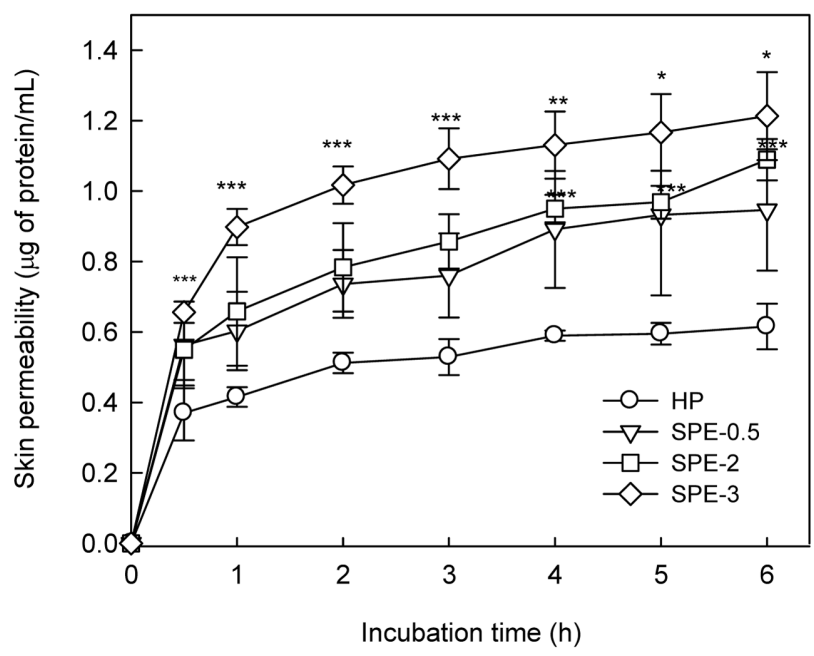

Fig. 4. Skin permeability of PE using Franz cell model. Values were analyzed with a repeated measurement independent $t$-test $(*$ : significantly different at $p<0.05$; **: significantly different at $p<0.01$; ***: significantly different at $p<0.001$ ). Each point represents mean \pm SEM. $n=3$. HP: Homogenate of placenta. SPE-0.5; subcritical extract of HP (SPE) for $0.5 \mathrm{~h}$ extraction, SPE-2; subcritical extract of HP (SPE) for $2 \mathrm{~h}$ extraction, SPE-3; subcritical extract of HP (SPE) for $4 \mathrm{~h}$ extraction

teristics of drugs. For in vitro transdermal studies, Franz diffusion cells are perhaps the most commonly used setups.

A permeability of HP and SPEs through rat skin was also conducted by using the Franz diffusion cells. The protein contents of the samples transported through the rat skin was significantly increased over time (Fig. 4). The skin permeability of the SPEs was higher than that of the HP.
SPE-3 showed highest skin permeation and significantly higher than HP. SPE-2 also showed significantly higher permeation than HP after $4 \mathrm{~h}$. As expected, increase of extraction time was found to significantly increase of skin permeability of subcritical extract of HP (SPE).

\section{Discussion}

In the previous studies, a variety of materials have been developed and are currently utilized as cosmetic additives or as medicinal products for the treatment of skin hyperpigmentation (An et al., 2005). Recently, the demand for natural products that inhibit or prevent skin pigmentation is increasing all over the world. A variety of natural or synthetic substances are currently utilized as ingredients of preparations designed to control hyperpigmentation, but none of these effect have proven completely, either due to their limited efficacy or safety concerns (Briganti et al., 2003).

Porcine placenta has been reported to have skin care effects, improve basic metabolic function and strengthen immune function (Kim et al., 2011). Although there are several types of placenta available, the use of human and bovine placenta is prohibited in cosmetics. In contrast, the porcine placenta is relatively safe and its immune effect is similar to that of humans origin so that it is used widely as cosmetic agent. Major components of the porcine placenta are proteins, amino acids, vitamins, minerals, and growth factors.

Effective components present in placental extract can be varied according to the method of preparation (Tonello et al., 1996), because the efficacy of placenta extract is highly dependent on manufacturing steps which include digestion, organic phase extraction, and autoclave/pasteurization processes. Since these manufacturing steps can denature effective and functional molecules derived from placenta, the efficacy of placental extract can be limited. To overcome these potential problems, we suggested a better way of placental extraction to preserve several bioactive molecules by means of a subcritical extraction.

The SPE showed lower protein content than HP and also decreased the antioxidant activity with increase of extraction time (Fig. 1 and Fig. 2). Wiboonsirikul et al. (2007) also reported that gradual decrease in both the protein content and radical scavenging activity was observed at the temperature. The carbohydrate content at $260^{\circ} \mathrm{C}$ was low and further decreased with the prolonged heating. Both the radical scavenging activity and the protein content also decreased with the increasing treatment time. However, it 
should be noted that while the reactants in the browning reaction substantially degraded, in particular, carbohydrate, the radical scavenging activity of the bran extract did not concomitantly decrease.

It is commonly agreed that the antioxidant activity of peptides may not be solely attributable to a single antioxidant mechanism, probably because the properties are derived from the presence of different amino acids favoring one mechanism over the others. Saiga et al. (2003) observed that the carboxyl and amino groups in the side chains of acidic and basic amino acids are thought to play an important role in chelating metal ions. Due to their abundance in skin gelatin hydrolysates, Gly, Pro and Hyp merit special consideration. Mendis et al. (2005) postulated that the antioxidant reactivity of squid skin gelatin was due to hydrophilic-hydrophobic partitioning in the peptide sequence.

In literature, porcine placenta extracts are reported to have good anti-wrinkle effect (Kim et al., 2010). Elastase inhibition effect of porcine amniotic fluid was increased monotonically as concentration of porcine amniotic fluid increased from 50 to $1,000 \mu \mathrm{g} / \mathrm{mL}$. At $500 \mu \mathrm{g} / \mathrm{mL}$ concentration, elastase inhibition of porcine placenta amniotic fluid was $33 \%$, whereas that of adenosine (reference material) was $14 \%$. $\mathrm{IC}_{50}(50 \%$ elastase inhibition concentration) of porcine amniotic fluid was $800 \mu \mathrm{g} / \mathrm{mL}$, whereas $\mathrm{IC}_{50}$ of porcine placenta extracts by enzyme treatment was $1,100 \mu \mathrm{g} / \mathrm{mL}$ in literature (Kim et al., 2011). Fig. 3 also showed inhibitory activity of HP and SPE. From our result, porcine PE has potential for anti-wrinkle agent as elastase inhibitor.

Recent studies on exploiting natural compounds for cosmetics industry have drawn much attention to the maximization of the bioactivity of extracts (Do et al., 2009). Wiechers (1989) reported that low molecular weight contributes to easier skin penetration, as there is an upper molecular weight limit for chemical compounds and drugs to be absorbed across the human skin barrier. Therefore, Bos and Meinardi (Bos and Meinardi, 2000) reported that certain skin penetration enhancers have low molecular weight. SPE-3 with high contents of A-N showed significantly higher permeation than HP (Fig. 4). Conclusively, the hydrolysis of SPE (especially SPE-3) has attracted attention as an effective means of enhancing the permeability and, consequently, the bioactivity of extracts.

\section{Acknowledgement}

This research was supported by Technology Development Program for Food, Ministry for Food, Agriculture,
Forestry and Fisheries, Republic of Korea.

\section{References}

1. Adler-Nissen, J. (1979) Determination of the degree of hydrolysis of food protein hydrolysates by trinitrobenzenesulfonic acid. J. Agric. Food Chem. 27, 1256-1262.

2. An, B. J., Kwak, J. H., Park, J. M., Lee, J. Y., Park, T. S., Lee, J. T., Son, J. H., Jo, C., and Byun, M. W. (2005) Inhibition of enzyme activities and the antiwrinkle effect of polyphenol isolated from the persimmon leaf (Diospyros kaki folium) on human skin. Dermatol. Surg. 31, 848-854.

3. Benzie, I. F. F. and Strain, J. (1996) The ferric reducing ability of plasma (FRAP) as a measure of "antioxidant power": the FRAP assay. Anal. Biochem. 239, 70-76.

4. Bos, J. D. and Meinardi, M. M. (2000) The 500 Dalton rule for the skin penetration of chemical compounds and drugs. Exp. Dermatol. 9, 165-169.

5. Briganti, S., Camera, E., and Picardo, M. (2003) Chemical and instrumental approaches to treat hyperpigmentation. Pigment Cell Res. 16, 101-110.

6. Do, Y.-K., Kim, J.-M., Chang, S.-M., Hwang, J.-H., and Kim, W.-S. (2009) Enhancement of polyphenol bio-activities by enzyme reaction. J. Mol. Catal. B-Enzym. 56, 173-178.

7. Fang, X. P., Xia, W. S., Sheng, Q. H., and Wang, Y. L. (2007) Purification and characterization of an immunomodulatory Peptide from bovine placenta water-soluble extract. Prep. Biochem. Biotechnol. 37, 173-184.

8. Georgieva, R., Stefanov, D., Fichorova, R., and Dimitrova, E. (1995) Effects of the whole extract and the chromatographic fractions of the pig placenta on lymphocyte proliferation and humoral immune response. Theriogenology 44, 539-551.

9. Gil-Izquierdo, A., Zafrilla, P., and Tomás-Barberán, F. A. (2002) An in vitro method to simulate phenolic compound release from the food matrix in the gastrointestinal tract. Eur. Food Res. Technol. 214, 155-159.

10. Hong, J. W., Lee, W. J., Hahn, S. B., Kim, B. J., and Lew, D. H. (2010) The effect of human placenta extract in a wound healing model. Ann. Plast. Surg. 65, 96-100.

11. Kim, B. Y., Kim, T., Kang, W. Y., Hyun, B., Cheon, H. Y., and Kim, D. (2010) Functional cosmetic effect of porcine placeta. Korean Chem. Eng. Res. 48, 327-331.

12. Kim, H. J., Lee, J. W., Kim, Y. I., and Lee, M. H. (2003) The effect of placental extract on the expression of tyrosinase, TRP-1 and TRP-2 in SK30 melanoma cells. Korean J. Dermatol. 41, 1612-1618.

13. Kim, T., Kim, S., Kang, W., Baek, H., Jeon, H. Y., Kim, B. Y., Kim, C. G., and Kim, D. (2011) Porcine amniotic fluid as possible antiwrinkle cosmetic agent. Korean J. Chem. Eng. 28, 1839-1843.

14. Kraunsoe, J. A. E., Claridge, T. D. W., and Lowe, G. (1996) Inhibition of human leukocyte and porcine pancreatic elastase by homologues of bovine pancreatic trypsin inhibitor. Biochemistry 35, 9090-9096.

15. Lee, K. H., Park, H. J., Seo, H. G., Kim, J. H., Lim, G. S., Lee, W. Y., Kim, N. H., Lee, J. H., Jung, H. S., Sung, S. H., and Song, 
H. (2013) Immune modulation effect of porcine placenta extracts in weaned the pig. J. Anim. Sci. (in press).

16. Mason, H. S. (1955) Reactions between quinones and proteins. Nature 175, 771 - 772.

17. McGregor, C. G., Davies, W. R., Oi, K., Teotia, S. S., Schirmer, J. M., Risdahl, J. M., Tazelaar, H. D., Kremers, W. K., Walker, R. C., Byrne, G. W., and Logan, J. S. (2005) Cardiac xenotransplantation: Recent preclinical progress with 3-month median survival. J. Thorac. Cardiovasc. Surg. 130, 844-851.

18. Mendis, E., Rajapakse, N., and Kim, S. K. (2005) Antioxidant properties of a radical-scavenging peptide purified from enzymatically prepared fish skin gelatin hydrolysate. J. Agric. Food Chem. 53, 581-587.

19. Nath, S. and Bhattacharyya, D. (2007) Cell adhesion by aqueous extract of human placenta used as wound healer. Indian J. Exp. Biol. 45, 732.

20. Pal, P., Mallick, S., Mandal, S. K., Das, M., Dutta, A. K., Datta, P. K., Bera, R., and Bhadra, R. (2002) A human placental extract: in vivo and in vitro assessments of its melanocyte growth and pigment-inducing activities. Int. J. Dermatol. 41, 760-767.

21. Pruitt, S. K., Kirk, A. D., Bollinger, R. R., Marsh Jr, H. C., Collins, B. H., Levin, J. L., Mault, J. R., Heinle, J. S., Ibrahim, S., and Rudolph, A. R. (1994) The effect of soluble complement receptor type 1 on hyperacute rejection of porcine xenografts. Transplantation 57, 363.

22. Saiga, A., Tanabe, S., and Nishimura, T. (2003) Antioxidant activity of peptides obtained from porcine myofibrillar proteins by protease treatment. J. Agric. Food Chem. 51, 36613667.

23. Sonavane, G., Tomoda, K., Sano, A., Ohshima, H., Terada, H., and Makino, K. (2008) In vitro permeation of gold nanoparticles through rat skin and rat intestine: Effect of particle size. Colloid Surface B 65, 1-10.
24. Tandon, H. and Prakash, A. (1972) Pathology of intestinal tuberculosis and its distinction from Crohn's disease. Gut 13, 260-269.

25. Tiwary, S. K., Shukla, D., Tripathi, A. K., Agrawal, S., Singh, M. K., and Shukla, V. K. (2006) Effect of placental-extract gel and cream on non-healing wounds. J. Wound Care 15, 325-328.

26. Togashi, S., Takahashi, N., Iwama, M., Watanabe, S., Tamagawa, K., and Fukui, T. (2002) Antioxidative collagen-derived peptides in human-placenta extract. Placenta 23, 497-502.

27. Tonello, G., Daglio, M., Zaccarelli, N., Sottofattori, E., Mazzei, M., and Balbi, A. (1996) Characterization and quantitation of the active polynucleotide fraction (PDRN) from human placenta, a tissue repair stimulating agent. J. Pharm. Biomed. Anal. 14, 1555-1560.

28. Wang, L. L. and Xiong, Y. L. (2005) Inhibition of lipid oxidation in cooked beef patties by hydrolyzed potato protein is related to its reducing and radical scavenging ability. J. Agric. Food. Chem. 53, 9186-9192.

29. Wiboonsirikul, J., Hata, S., Tsuno, T., Kimura, Y., and Adachi, S. (2007) Production of functional substances from black rice bran by its treatment in subcritical water. LWT-Food Sci. Technol. 40, 1732-1740.

30. Wiechers, J. W. (1989) The barrier function of the skin in relation to percutaneous absorption of drugs. Pharm. Weekbl. Sci. 11, 185-198.

31. Wrathall, A. E. (1997) Risks of transmitting scrapie and bovine spongiform encephalopathy by semen and embryos. Rev. Sci. Tech. 16, 240-264.

32. Zhang, C., Lu, Y., Tao, L., Tao, X., Su, X., and Wei, D. (2007) Tyrosinase inhibitory effects and inhibition mechanisms of nobiletin and hesperidin from citrus peel crude extracts. J. Enzyme Inhib. Med. Chem. 22, 83-90.

(Received 2013.4.6/Revised 2013.6.1/Accepted 2013.6.12) 